\title{
Correspondence
}

\section{Medical data: the choice to opt out}

You accuse the National Health Service (NHS) in England of using "sleight of hand" in the way we are advertising the care.data programme (see go.nature. com/srp5nu), suggesting that we should make it clearer to people that the programme poses potential risks to their privacy and that they can opt out of it (Nature 505, 261; 2014). We believe that this accusation is unwarranted.

"You have a choice" is written in bold on the cover of the leaflet about the programme, which is being sent to every household in the country. The leaflet goes on to say: "If you do not want information that identifies you to be shared outside your GP [general practitioner] practice, please ask the practice to make a note of this in your medical record."

Last month, we published a detailed assessment of the potential negative and positive impacts of the programme on privacy (see go.nature.com/ xcqaql). And, most importantly, patients have the opportunity to discuss the changes with a trained adviser and with their GP.

It would be unethical to introduce this opt-out system without proper publicity, as well as illegal under the UK Data Protection Act 1998. This accounts for the scale of our awareness-raising strategy and our advice last August to all GP practices to start telling people about the proposed changes. Geraint Lewis NHS England, Leeds, UK.

geraint.lewis@nhs.net Competing financial interests declared: see go.nature.com/ sluxqa for details.

\section{Medical data: widen use in research}

The Wellcome Trust and other UK medical-research charities support the plans of the National Health Service (NHS) in England to make better use of information from patients' records, but we have no wish to downplay the right of people to opt out of the NHS care.data programme (go. nature.com/srp5nu), as you imply (Nature 505, 261; 2014). Like you, we believe it is critical that the risks, benefits and choices are explained clearly to everyone.

We have launched a campaign to support the wider use of medical records for research through mechanisms such as the Clinical Practice Research Datalink, rather than the care.data programme specifically (see www.patientrecords.org. uk). It is intended to complement NHS England's communications by highlighting the choices people have alongside the research benefits we perceive, and to help people to reach an informed decision.

Those with concerns about sharing patient data are right in that no system can guarantee protection against determined misuse. We have confidence, however, in the strict safeguards that govern the research use of medical records, which can manage those risks while enabling research to benefit from a national cradle-to-grave data set. Jeremy Farrar Wellcome Trust, London, UK.

j.farrar@wellcome.ac.uk Competing financial interests declared: see go.nature.com/lskrj4 for details.

\section{Planck team replies to data 'anomalies'}

We would like to clarify some points arising from your News report on the debate over data from the European Space Agency's Planck mission (see Nature http://doi.org/q8t; 2013).

The cosmological parameters estimated by the Planck Collaboration are statistically compatible with those estimated by NASA's Wilkinson Microwave Anisotropy Probe (see G. Hinshaw et al. Astrophys J. Suppl. S. 208, 19; 2013). Also, the analysis of the Planck data by David Spergel and colleagues (see preprint at http://arxiv.org/ abs/1312.3313; 2013) is actually in close agreement with our own (http://arxiv.org/abs/1303.5076; 2013): the values of their parameters are within one standard deviation of ours.

For example, their value of the Hubble constant is within 0.6 of a standard deviation of ours; the matter density and the amplitude of the fluctuation spectrum differ by about one standard deviation. These differences, which are not evident in our analyses of the Planck data, could be caused by methodological variations between the respective analyses rather than by systematic errors in the Planck data.

We, and Spergel and colleagues, have verified that the small, timedependent systematic errors that affect a subset of the data at a radio frequency of 217 gigahertz, which we reported on in the revised versions of the Planck papers from 2013, have little impact on the Planck Collaboration's cosmological results.

Jan Tauber European Space Agency, Noordwijk, the Netherlands, and the Planck Science Team (see go.nature.com/ q5ltry), on behalf of the Planck Collaboration.

jtauber@rssd.esa.int

\section{Carbon dioxide storage is secure}

The Sleipner gas field in the North Sea has the world's first purposeengineered subsea geological storage site for carbon dioxide. Contrary to your headline's implication, seabed fractures do not pose any threat to this project (Nature 504, 339-340; 2013).

Independent researchers have analysed extensive data from site monitoring using seismicreflection surveys of the deep subsurface (both before $\mathrm{CO}_{2}$ injection and then at two-year intervals); they found that performance is excellent, with no evidence of any $\mathrm{CO}_{2}$ leakage (see A. J. Cavanagh and R. S. Haszeldine, Int. J. Greenh. Gas Con. 21, 101-112; 2014).

Your graphic, which juxtaposes stored $\mathrm{CO}_{2}$ with fractures, is also misleading: Sleipner is in fact 25 kilometres away from the fracture described and is overlain by 500 metres of sealing mudrock from the estimated depth of the crack. Elsewhere beneath the North Sea, mudrocks have retained natural $\mathrm{CO}_{2}$ for tens of millions of years.

The suggestion that leakage would be "a disaster for public opinion" is unsupported. Socialscience research indicates that unintended leakage need not be a show-stopper (see L. Mabon et al. Mar. Policy 45, 9-15; 2014). More than guarantees that sites will never leak, the public seeks reassurance that site selection minimizes leakage risk, and that monitoring and remediation procedures are in place should a leak be discovered.

There are many known fluid conduits beneath the North Sea, but there is no evidence of unplanned $\mathrm{CO}_{2}$ or methane movement in the rocks overlying the storage site. Since the Sleipner project was set up 20 years ago, global endeavours have improved the geoscientific identification, operation and monitoring of $\mathrm{CO}_{2}$ storage (see V. Scott et al. Nature Clim. Change 3, 105-111; 2013). Sleipner's $\mathrm{CO}_{2}$ is securely retained by residual saturation in the reservoir, multiple mudrock seals, and eventual dissolution and dispersion in pore waters. Vivian Scott ${ }^{\star}$ Edinburgh

University, UK.

vivian.scott@ed.ac.uk ${ }^{*}$ On behalf of 6 co-signatories (see go.nature.com/zivosz for full list).

CONTRIBUTIONS

Correspondence may be sent to correspondence@ nature.com after consulting the guidelines at go.nature.com/cmchno Alternatively, readers may comment online: www. nature.com/nature. 